\title{
Stability of the acrosome of the brush-tailed possum (Trichosurus vulpecula) and tammar wallaby (Macropus eugenii) in vitro and after exposure to conditions and agents known to cause capacitation or acrosome reaction of eutherian spermatozoa
}

\author{
K. E. Mate and J. C. Rodger \\ Department of Biological Sciences, University of Newcastle, New South Wales 2308, Australia
}

\begin{abstract}
Summary. Ejaculated spermatozoa from brush-tailed possums and tammar wallabies were washed by a 'swim up' procedure into Hanks Balanced Salt Solution (HBSS), and then exposed to test solutions. Spermatozoa were incubated at $33^{\circ} \mathrm{C}$, or room temperature when long-term sperm survival $(>10 \mathrm{~h}$ ) was required. Exposure of spermatozoa to calcium ionophore A23187, cyclic nucleotides, phosphoinositide pathway intermediates, lysophospholipids, trypsin or 'capacitating' high ionic-strength medium ( $380 \mathrm{mosmol}$ ) followed by $3 \%$ bovine serum albumin for periods up to $24 \mathrm{~h}$ did not induce acrosomal loss. However, there were major changes within the acrosome: large numbers of empty membrane-bound vesicles were formed, the electron density of the acrosomal matrix decreased and the acrosome swelled slightly. The origin of the vesicles is unclear but the acrosomal membranes and the plasma membrane remained intact.
\end{abstract}

Keywords: marsupial; spermatozoa; acrosome reaction; capacitation; ionophore

\section{Introduction}

To fertilize an egg the spermatozoa of eutherian mammals must go through post-ejaculatory functional changes known as capacitation (Chang, 1951; Austin, 1952; Yanagimachi, 1988). The precise nature of capacitation remains elusive but it probably involves the removal of surface coating materials and increased permeability to metal ions (Oliphant et al., 1985; Meizel, 1985) rendering spermatozoa capable of undergoing the acrosome reaction (Bedford, 1983). In eutherian mammals the acrosome reaction is an exocytotic event involving multiple point fusion of the plasma membrane and outer acrosomal membrane which results in release of the acrosomal contents (Barros et al., 1967; Yanagimachi, 1988).

Fertilization and related events have been examined morphologically for three marsupial species (Rodger \& Bedford, 1982a, b; Baggott et al., 1987; Breed \& Leigh, 1988). However, the character of the acrosome reaction is not known and whether marsupial spermatozoa require capacitation remains an open question. The moderate to long time periods that marsupial spermatozoa spend in the female tract before fertilization (see Selwood \& McCallum, 1987) suggest that they may require capacitation but this has not yet been examined directly for any marsupial. Marsupial gamete structure, function and interaction at fertilization were the subject of a recent review (Rodger, 1991).

Although the mechanisms of capacitation in vivo remain elusive, it can be readily induced in several eutherian species by a variety of culture conditions (Rogers, 1978; Yanagimachi, 1988). Similarly, the acrosome reaction, a $\mathrm{Ca}^{2+}$-dependent event, can be induced by calcium ionophores 
and cell activators such as cyclic nucleotides, phorbol esters and diacylglycerols (e.g. Meizel, 1985; Lee et al., 1987; Yanagimachi, 1988).

The marsupial acrosome does not form a cap over the sperm head as in eutherian mammals, but is a smaller structure covering only about the anterior third of the 'dorsal' surface of the sperm head in possums and kangaroos (Harding et al., 1979; Temple-Smith, 1987). In addition, the acrosome appears not to be divided into regions and probably does not contain an equatorial segment, the site of fusion with the cell membrane of the eutherian oocyte (Bedford et al., 1979; Yanagimachi, 1988).

The present study began with the simple assumption that the calcium ionophore A23187 could be used to study the character of the acrosome reaction of marsupial spermatozoa. When it was not affected by such treatment, a survey of the response of the marsupial acrosome to various agents known to induce the acrosome reaction of eutherian spermatozoa was initiated. When all failed to produce the expected exocytotic response the effects of capacitating treatments and pretreatment were also examined.

\title{
Materials and Methods
}

\begin{abstract}
Animals and semen. Adult male brush-tailed possums (Trichosurus vulpecula) were captured in the Newcastle area and housed as described by Rodger \& Mate, (1988) in a $14 \mathrm{~h}$ light:10 h dark cycle. Tammar wallabies (Macropus eugenii) were from the colony of the CSIRO division of Wildlife and Ecology in Canberra. They were housed in outside yards at the University of Newcastle Animal House and fed a diet of rabbit pellets, lucerne and natural grass. A pool of 8 possums and 2 wallabies was used as the source of spermatozoa.

Semen was collected by electroejaculation under general anaesthesia induced by alphaxalone/alphadolone acetate (Saffan: Glaxo Australia, Boronia, Victoria, Australia; $1.5 \mathrm{ml} / \mathrm{kg}$, i.m.) or halothane (Fluothane: ICI Australia, Melbourne, Australia; by mask $2 \cdot 5-3 \cdot 5 \%, 2$ litres $\mathrm{O}_{2} / \mathrm{min}$ ). Electroejaculation was carried out as described previously (Rodger \& White, 1978; Rodger \& Pollitt, 1981). Possums were ejaculated approximately every 14 days and wallabies every 7 days with no sign of adverse effects. Individual or pooled sperm samples were used depending upon sperm concentration and experimental requirements.
\end{abstract}

The mean sperm concentration during the experimental period for the possum ejaculates was $15.6 \times 10^{6}$ spermatozoa/ml and for the tammar was $119 \times 10^{6}$ spermatozoa $/ \mathrm{ml}$. Semen volume varied between 0.5 and $10 \mathrm{ml}$ for the possum, whilst wallaby ejaculates were generally less than $\mathrm{I} \mathrm{ml}$ and were therefore collected into $30 \mathrm{ml}$ Dulbecco's phosphate-buffered saline (PBS), pH 7.6 (Flow Laboratories, Melbourne, Australia) to prevent coagulation. Ejaculates exhibiting poor percentage or progressive sperm motility or concentration $<5 \times 10^{6} / \mathrm{ml}$ were discarded. Spermatozoa were scored for percentage motility $(0-100 \%)$ and progressive motility $(0-5)$ before and after washing.

The medium used throughout the study was Hank's Balanced Salt Solution (HBSS), 300 mosmol supplemented with $0.09 \mathrm{~mm}$-pyruvate, $9 \mathrm{~mm}$-lactate, 75 i.u. penicillin $/ \mathrm{ml}, 0.05 \mathrm{mg}$ streptomycin $/ \mathrm{ml}$ and $2 \%$ bovine serum albumin (BSA) at $\mathrm{pH} 7.6$, which was found to be optimum for sperm survival (K. E. Mate \& J. C. Rodger, unpublished) and satisfied the minimum requirements for capacitation and fertilization of mammalian spermatozoa (Rogers, 1978). Various other salt solutions and media have been tested, including Krebs'-Ringer phosphate, Krebs'-Henseleit Ringer, Dulbecco's phosphate-buffered saline, Dulbecco's modified Eagles medium (Flow Laboratories), all adjusted to $\mathrm{pH} 7 \cdot 6$, which maintain possum and wallaby spermatozoa viability in vitro (K. E. Mate \& J. C. Rodger, unpublished).

Possum semen was diluted 1:1 with medium before washing to decrease the viscosity and improve the efficiency of the washing procedure. Spermatozoa were washed by layering $0.5 \mathrm{ml}$ diluted semen beneath $0.5 \mathrm{ml}$ culture medium in a 3-ml plastic culture tube and then left vertical for 30 $60 \mathrm{~min}$ at room temperature for spermatozoa to 'swim up' into the medium. Spermatozoa were then collected with a Pasteur pipette from the top layer. Washing marsupial spermatozoa by the 'swim up' technique described here provides a highly motile $(100 \%$; progressive motility $=5)$ and concentrated sperm preparation free of seminal plasma and prostatic bodies which is suitable for in-vitro culture. The concentrations of spermatozoa recovered from the 'swim up' preparation were between I and $5 \times 10^{6}$ spermatozoa $/ \mathrm{ml}$.

Spermatozoa were pelleted by centrifugation at $700 \mathrm{~g}$ for $10 \mathrm{~min}$ and resuspended in the test solution. Agents and conditions tested were as follows.

Calcium influx: calcium ionophore A23187 (0.01-100 $\mu \mathrm{M})\left(\mathrm{Ca}^{2+} / \mathrm{Mg}^{2+}\right.$ mixed salts Sigma cat. No. C5149, Sigma Chemical Co., St Louis, MO, USA), incubated in the dark.

Cyclic nucleotides: dibutyryladenosine cyclic monophosphate $(0 \cdot 01-10 \mu \mathrm{M})$ (Sigma cat. No. D0627) and dibutyrylguanosine cyclic monophosphate $(0.01-10 \mu \mathrm{M})$ (Sigma cat. No. D3510).

Phosphoinositide pathway agents: 1,2-dioctanoyl-sn glycerol $(0 \cdot 1-50 \mu \mathrm{M})$ (Sigma cat. No. D5156) and phorbol 12-myristate 13-acetate (1-1000 nM) (Sigma cat. No. P8139).

Membrane fusigen: lysophosphatidylcholine (1.4-85 $\mathrm{g} / \mathrm{ml}$ ) (Sigma cat. No. L4129).

Lytic enzyme: trypsin $(0 \cdot 5-5 \%)$ (Boehringer, Mannheim, FRG). 
Capacitating treatment (HIS/BSA): high ionic-strength HBSS (HBSS supplemented to 380 mosmol with $2.5 \mathrm{mg} / \mathrm{ml} \mathrm{NaCl}$ ) followed by HBSS containing 3\% BSA (Brackett \& Oliphant, 1975).

Sequential treatment: HIS/BSA treatment as above followed by calcium ionophore A23187 (1 or $10 \mu \mathrm{M})$. Control for sequential treatment was HIS/BSA treatment followed by HBSS.

Spermatozoa were incubated at $33^{\circ} \mathrm{C}$, or at room temperature when long-term survival was required. Preliminary experiments showed that possum spermatozoa do not tolerate incubation at $37^{\circ} \mathrm{C}$ (possum body temperature is $35^{\circ} \mathrm{C}$ ) but survival of good motility ( $>70 \%$ for $>5 \mathrm{~h}$ ) was achieved at $33^{\circ} \mathrm{C}$ and long-term survival ( $>24 \mathrm{~h}$ ) when spermatozoa were incubated at room temperature. Only short-term incubation of tammar spermatozoa was tested in this study. Motility was assessed and scored hourly using phase-contrast microscopy. At the completion of the incubation period acrosomal status was scored for 100-200 spermatozoa per treatment by two methods.

Head decondensation. Sperm nuclei were decondensed by diluting the sperm suspension 1:1 with a solution of $1 \mathrm{M}-\mathrm{CaCl}_{2}$ and $1 \mathrm{M}-\mathrm{MgCl}_{2}$. To obtain maximum head decondensation spermatozoa were left for $10 \mathrm{~min}$ before examination of the acrosomes by phase-contrast microscopy. The extent to which possum spermatozoa nuclei decondensed in response to high levels of $\mathrm{Ca}^{2+}$ and $\mathrm{Mg}^{2+}$ was, however, highly variable between samples. Partial decondensation resulted in spots of condensed refractory nuclear material remaining in the head region of the spermatozoa which were often indistinguishable from the acrosome. Although decondensation of spermatozoa was useful for a rapid qualitative assessment, the Bryan's stain method proved to be more reliable for quantifying acrosome numbers and all data presented were based on stained preparations.

Bryan's stain. Spermatozoa were fixed for $10 \mathrm{~min}$ by adding $500 \mu \mathrm{l}$ sperm suspension to $3 \mathrm{ml} 2 \%$ paraformaldehyde in PBS, pH 7.4. Spermatozoa were attached to slides using the Cytospin 2 system (Shandon Inc., Pittsburgh, PA, USA) at $210 \mathrm{~g}$ for $3 \mathrm{~min}$ or attached to coverslips by resuspending in $50 \mathrm{~mm}$-glycine in PBS and allowing them to settle overnight. Acrosomes were visualized (Fig. 1) by staining for 3 min in Bryan's stain (Bryan, 1970). It is quite critical that the correct dye variants be used to obtain staining with this method. Reagents used were eosin Y (Sigma No. E4382), fast green FCF (Sigma No. F7258) and flavianic acid (Sigma No. F6500).

Electron microscopy. Acrosomal status of 100 spermatozoa per treatment was also assessed by electron microscopy. Both longitudinal and transverse sections were assessed providing that a significant portion of acrosomal matrix (at least one-third of maximal width) was clearly visible. Acrosomes were classified as being slightly vesiculated when more than 3 small vesicles were present and as markedly vesiculated when more than about $50 \%$ of the acrosomal matrix was occupied by vesicles. Typical examples of non-, slightly and markedly vesiculated acrosomes are shown in Fig. 2. For EM processing, spermatozoa from the test solutions were centrifuged at $210 \mathrm{~g}$ for $5 \mathrm{~min}$ and $1 \mathrm{drop}$ of the concentrated spermatozoa was fixed in $2 / 3$ Superfix (final concentrations: $0.15 \mathrm{M}$-sodium cacodylate; $1.8 \%$ paraformaldehyde; $0.01 \%$ picric acid; $3.2 \%$ glutaraldehyde; $1.7 \mathrm{mM}-\mathrm{Ca}^{2+}$ ) in a $0.4-\mathrm{ml}$ centrifuge tube and then pelleted by centrifuging at $700 \mathrm{~g}$ for $10 \mathrm{~min}$. The pellet was then cut from the tube and fixation continued with $1 \%$ osmium tetroxide followed by uranyl acetate. The blocks were dehydrated through acetone and embedded in Spurr's resin. Thin sections were stained with uranyl acetate and lead citrate and examined in a Jeol 100-CX electron microscope.

\section{Results}

Incubating possum and wallaby spermatozoa with the calcium ionophore A23187 did not induce acrosome loss in any of the culture conditions tested (Fig. 1). At no time did the percentage of spermatozoa without acrosomes exceed $3 \%$ which is identical to the levels in the control (Tables 1 $\& 2)$. The highest concentrations of ionophore tested ( $100 \mu \mathrm{M}$, at least 10 times that commonly used to induce the acrosome reaction in eutherian species) destroyed the structural integrity of the spermatozoa but the acrosome remained intact. Alterations to $\mathrm{pH}$ of the solution, temperature and time of exposure to the ionophore did not affect the result. Similarly, acrosomal loss was not induced when marsupial spermatozoa were incubated with any of the other cell activators/ regulators.

Addition of agents had variable but non-significant effects on motility except for $100 \mu \mathrm{M}-$ ionophore and lysophosphatidylcholine at concentrations above $40 \mu \mathrm{g} / \mathrm{ml}$ which abolished motility completely (Tables 1 \& 2).

Electron microscopy confirmed the presence of the acrosome and that an exocytotic event characteristic of the eutherian acrosome reaction had not occurred in response to any of the treatments. However, changes were observed within the acrosomal matrix. Possum spermatozoa incubated in HIS/BSA medium for $1 \mathrm{~h}$ at $33^{\circ} \mathrm{C}$ showed extensive vesiculation of the acrosomal matrix. Large numbers of empty membrane-bound vesicles were formed within the acrosome, the electron density of the acrosomal matrix decreased and the acrosome swelled slightly (Fig. 2). The vesicles appeared to arise as buds from the outer acrosomal membrane (Fig. 2) but both the acrosomal and 

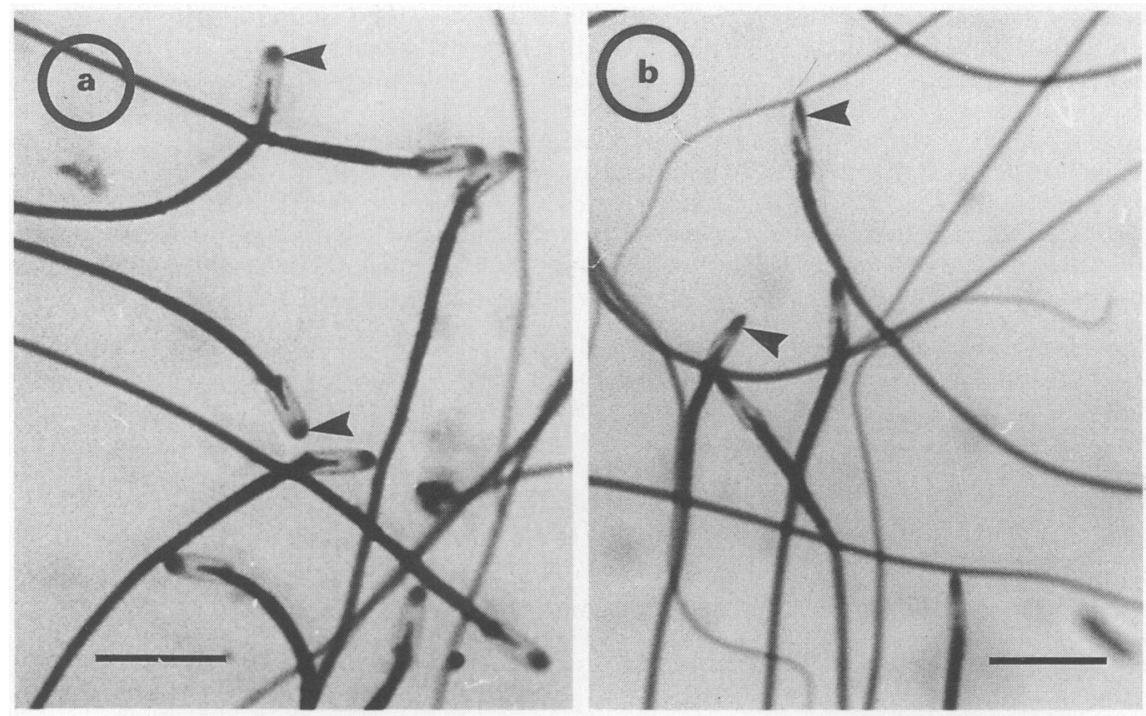

Fig. 1. Spermatozoa from possum (a) and wallaby (b) stained with Bryan's stain. All spermatozoa have an acrosome at the apical tip of the head (arrows). Viewed from the dorsal aspect the possum acrosome is a circular shaped spot and the wallaby acrosome oval. Wallaby spermatozoa occasionally orientate laterally on the slide and the acrosome appears wedge shaped (top centre). Bars $=10 \mu \mathrm{m}$.

Table 1. The response of the acrosomes of brush-tailed possum (Trichosurus vulpecula) spermatozoa to incubation under conditions which result in capacitation or acrosome reaction of eutherian spermatozoa

\begin{tabular}{|c|c|c|c|c|c|c|}
\hline \multirow[b]{2}{*}{ Treatment } & \multicolumn{2}{|c|}{$\begin{array}{c}\text { Motility } \\
(\text { mean } \pm \text { s.e.m.; } n=3 \text { ) }\end{array}$} & \multirow{2}{*}{$\begin{array}{c}\% \\
\text { Acrosome } \\
\text { present } \dagger\end{array}$} & \multicolumn{3}{|c|}{$\begin{array}{l}\% \text { Acrosome vesiculation } \\
(\text { mean } \pm \text { s.e.m.; } n=3)\end{array}$} \\
\hline & $\%$ & Score & & None & Slight & Marked \\
\hline Time 0 & $98 \pm 1$ & $5 \cdot 0 \pm 0 \cdot 0$ & 99 & $76 \pm 5 \cdot 0^{a}$ & $15 \pm 2 \cdot 3$ & $9 \pm 2.6$ \\
\hline $\begin{array}{l}\text { Incubation for } 1 \mathrm{~h} \\
\text { HBSS } \\
\text { HIS/BSA } \\
1 \mu \mathrm{M}-\mathrm{A} 23187 \\
10 \mu \mathrm{M}-\mathrm{A} 23187\end{array}$ & $\begin{array}{l}92 \pm 1 \\
80 \pm 11 \\
55 \pm 17 \\
58 \pm 21\end{array}$ & $\begin{array}{l}5 \cdot 0 \pm 0.0 \\
4 \cdot 3 \pm 0.5 \\
2 \cdot 7 \pm 0.8 \\
2 \cdot 7 \pm 1 \cdot 0\end{array}$ & $\begin{array}{l}99 \\
98 \\
98 \\
97\end{array}$ & $\begin{array}{l}46 \pm 8 \cdot 5^{\mathrm{a}} \\
29 \pm 8 \cdot 3^{\mathrm{b}} \\
47 \pm 7 \cdot 9^{\mathrm{a}} \\
33 \pm 11\end{array}$ & $\begin{array}{l}27 \pm 2 \cdot 6 \\
25 \pm 2 \cdot 6 \\
28 \pm 5 \cdot 9 \\
17 \pm 4 \cdot 1\end{array}$ & $\begin{array}{l}27 \pm 6 \cdot 4 \\
46 \pm 10 \cdot 2 \\
25 \pm 4 \cdot 5 \\
34 \pm 6 \cdot 8+\end{array}$ \\
\hline $\begin{array}{l}\text { Sequential incubation for } 21 \\
\text { HIS/BSA/HBSS } \\
\text { HIS/BSA/1 } \mu \mathrm{M}-\mathrm{A} 23187 \\
\text { HIS/BSA/10 } \mu \mathrm{M}-\mathrm{A} 23187\end{array}$ & $\begin{array}{l}87 \pm 4 \\
73 \pm 6 \\
78 \pm 5\end{array}$ & $\begin{array}{l}4 \cdot 7 \pm 0 \cdot 2 \\
4 \cdot 0 \pm 0 \cdot 4 \\
4 \cdot 3 \pm 0 \cdot 2\end{array}$ & $\begin{array}{l}99 \\
98 \cdot 5 \\
97\end{array}$ & $\begin{array}{l}28 \pm 1 \cdot 4^{b} \\
25 \pm 4 \cdot 9^{b} \\
23 \pm 4.9^{b}\end{array}$ & $\begin{array}{l}36 \pm 0 \cdot 7 \\
33 \pm 4 \cdot 3 \\
35 \pm 3 \cdot 5\end{array}$ & $\begin{array}{l}36 \pm 0.7 \\
42 \pm 2.9 \\
42 \pm 8.5\end{array}$ \\
\hline $\begin{array}{l}\text { Incubation for } 20 \mathrm{~h} \S \\
\text { HBSS } \\
\text { HIS/BSA } \\
1 \mu \mathrm{M}-\mathrm{A} 23187 \\
10 \mu \mathrm{M}-\mathrm{A} 23187\end{array}$ & $\begin{array}{l}33 \pm 21 \\
27 \pm 15 \\
55 \pm 8 \\
20 \pm 5\end{array}$ & $\begin{array}{l}1.0 \pm 0.4 \\
1.0 \pm 0.0 \\
1.5 \pm 0.3 \\
1.5 \pm 0.3\end{array}$ & $\begin{array}{l}98 \\
97 \\
99 \\
99\end{array}$ & & & \\
\hline
\end{tabular}

Treatments with different letter superscripts were significantly different at the $5 \%$ level by Student's $t$ test.

These statistics compared numbers of spermatozoa with non-vesiculated acrosomes to detect any increase in vesiculation due to the treatment.

† Means only, all s.e.m. $<1(n=3)$.

$\$$ The remaining $16 \pm 7.0 \%$ spermatozoa were so damaged by ionophore treatment that the acrosomes could not be classified. This treatment group was not included in the statistical analysis.

$\S$ Not examined by electron microscopy. 
Table 2. The response of the acrosomes of tammar wallaby (Macropus eugenit) spermatozoa to incubation under conditions which result in capacitation or acrosome reaction of eutherian spermatozoa

\begin{tabular}{|c|c|c|c|c|c|c|}
\hline \multirow[b]{2}{*}{ Treatment } & \multicolumn{2}{|c|}{$\begin{array}{c}\text { Motility } \\
(\text { mean } \pm \text { s.e.m.; } n=3)\end{array}$} & \multirow{2}{*}{$\begin{array}{c}\% \\
\text { Acrosome } \\
\text { present } \dagger\end{array}$} & \multicolumn{3}{|c|}{$\begin{array}{l}\% \text { Acrosome vesiculation } \\
(\text { mean } \pm \text { s.e.m.; } n=3)\end{array}$} \\
\hline & $\%$ & Score & & None & Slight & Marked \\
\hline Time 0 & $98 \pm 1$ & $5 \cdot 0 \pm 0 \cdot 0$ & $99 \cdot 6$ & $87 \pm 3 \cdot 5^{a}$ & $10 \pm 4 \cdot 0$ & $3 \pm 2 \cdot 4$ \\
\hline $\begin{array}{l}\text { Incubation for } 1 \mathrm{~h} \\
\text { HBSS } \\
\text { HIS/BSA } \\
1 \mu \mathrm{M}-\mathrm{A} 23187 \\
10 \mu \mathrm{M}-\mathrm{A} 23187\end{array}$ & $\begin{array}{l}95 \pm 0 \\
75 \pm 11 \\
95 \pm 0 \\
35 \pm 25\end{array}$ & $\begin{array}{l}5 \cdot 0 \pm 0 \cdot 0 \\
3 \cdot 3 \pm 1 \cdot 0 \\
5 \cdot 0 \pm 0 \cdot 0 \\
2 \cdot 6 \pm 1 \cdot 5\end{array}$ & $\begin{array}{r}99 \cdot 6 \\
99 \cdot 6 \\
99 \cdot 6 \\
100\end{array}$ & $\begin{array}{l}84 \pm 3 \cdot 3^{\mathrm{a}} \\
80 \pm 3 \cdot 1^{\mathrm{a}} \\
51 \pm 15 \cdot 0^{\mathrm{a}} \\
11 \pm 2 \cdot 3^{\mathrm{b}}\end{array}$ & $\begin{array}{l}14 \pm 3 \cdot 3 \\
14 \pm 2 \cdot 9 \\
20 \pm 3 \cdot 9 \\
34 \pm 9 \cdot 2\end{array}$ & $\begin{array}{r}2 \pm 1.0 \\
7 \pm 1.9 \\
29 \pm 11.4 \\
55 \pm 6.9\end{array}$ \\
\hline $\begin{array}{l}\text { Sequential incubation for } 2 \\
\text { HIS/BSA/HBSS } \\
\text { HIS/BSA } / 1 \mu \mathrm{M}-\mathrm{A} 23187 \\
\text { HIS/BSA } / 10 \mu \mathrm{M}-\mathrm{A} 23187\end{array}$ & $\begin{array}{l}92 \pm 2 \\
27 \pm 7 \\
33 \pm 23\end{array}$ & $\begin{array}{l}4.6 \pm 0.3 \\
3.0 \pm 0.9 \\
2.7 \pm 1 \cdot 1\end{array}$ & $\begin{array}{l}99 \cdot 6 \\
99 \\
99 \cdot 3\end{array}$ & $\begin{array}{l}80 \pm 9 \cdot 5^{\mathrm{a}} \\
67 \pm 4 \cdot 3^{\mathrm{a}} \\
91 \pm 3 \cdot 8^{\mathrm{a}}\end{array}$ & $\begin{array}{r}10 \pm 2 \cdot 5 \\
19 \pm 1 \cdot 5 \\
7 \pm 2.9\end{array}$ & $\begin{array}{r}10 \pm 7 \cdot 4 \\
14 \pm 4 \cdot 3 \\
2 \pm 1 \cdot 4\end{array}$ \\
\hline
\end{tabular}

Treatments with different letter superscripts were significantly different at the $5 \%$ level by Student's $t$ test.

These statistics compared numbers of spermatozoa with non-vesiculated acrosomes to detect any increase in vesiculation due to the treatment.

†Means only, all s.e.m. $<1(n=3)$.

plasma membranes remained intact and there was no evidence of fusion of these membranes at any point. Vesiculation occurred to a lesser extent in the control spermatozoa incubated in HBSS which may be a consequence of the relatively high levels of BSA present in the standard incubation medium. None of the other treatments increased the degree of vesiculation above that in HBSS alone (Table 1).

Wallaby spermatozoa exhibited vesiculation similar to that seen in the HIS/BSA-treated possum spermatozoa after treatment with $10 \mu \mathrm{M}$-A23187 but not HIS/BSA (Table 2). A two-step treatment of possum spermatozoa, HIS/BSA for $1 \mathrm{~h}$ followed by ionophore for $1 \mathrm{~h}$, did not increase the degree of vesiculation. However, prior treatment of wallaby spermatozoa with HIS/BSA abolished the response to ionophore (Table 2).

\section{Discussion}

These results indicate that marsupial spermatozoa have unusually stable acrosomes. Agents which induce an exocytotic acrosome reaction in eutherian and invertebrate spermatozoa, such as the calcium ionophore A23187, and a broad range of other cell activation agents are unable to do so in possum and wallaby spermatozoa. The maximum acrosome loss achieved after 1-h incubation under all conditions tested was only $3 \%$ (Tables $1 \& 2$ ). Eutherian spermatozoa could be expected to lose as much as $40 \%$ or more of their acrosomes under simple control incubation conditions and $>90 \%$ after treatment with high levels of ionophore (see Shams-Borhan \& Harrison, 1981; Dudenhausen \& Talbot, 1982).

The acrosome of the eutherian spermatozoon is generally its weakest point. Any disruption to sperm integrity (e.g. by freezing and thawing) is likely to be first evident as loss of the acrosome. The fragility of the eutherian acrosome has led to the suggestion that capacitation involves the removal of acrosome stabilizing agents which prevent premature acrosome reaction in the male and female tracts (Bedford, 1983). In contrast, marsupial spermatozoa appear to possess unusually stable acrosomes which remain intact after exposure to the wide variety of agents and conditions described here and major disruption of the cell (freeze/thawing without cryoprotectant; K. E. Mate \& J. C. Rodger, unpublished) or decondensation of the non-disulphide stabilized nucleus by air 

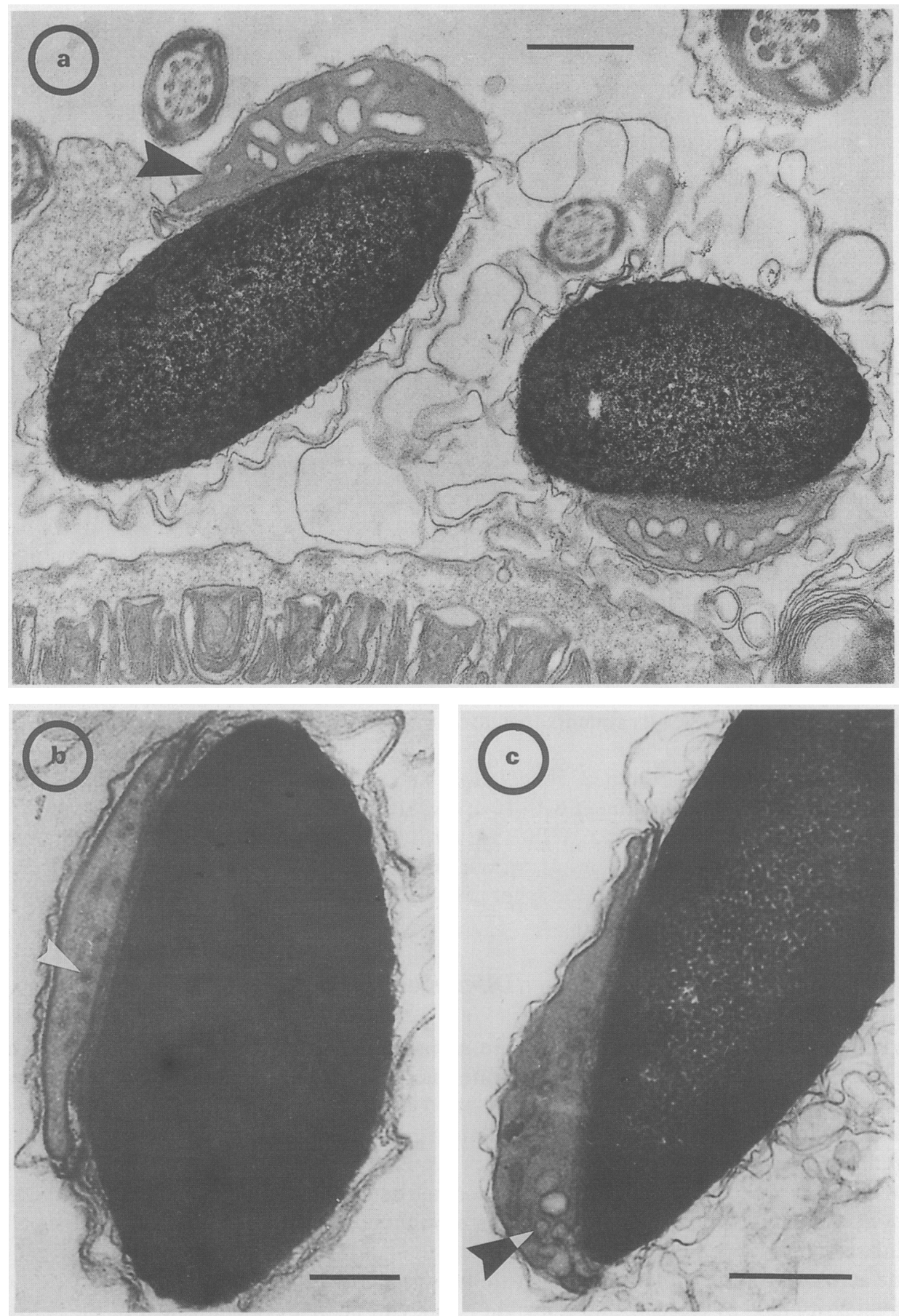

Fig. 2. Electron micrographs of possum spermatozoa. (a) Two HIS/BSA-treated spermatozoa with 'marked' vesiculation of their acrosomes. Note the apparent budding of the acrosomal membrane to form the vesicles (arrow). Bar $=0.5 \mu \mathrm{m}$. (b) Control spermatozoon with a nonvesiculated acrosome. The acrosomes of freshly ejaculated spermatozoa often contained small vacuities (arrow). These are remnants of the acrosomal compaction process which occurs in the epididymis. Bar $=0.25 \mu \mathrm{m}$. (c) An incubated spermatozoon illustrating 'slight' vesiculation of the acrosome (arrow). Bar $=0.5 \mu \mathrm{m}$. 
drying, treatment with detergent (Triton X-100) or divalent cations $\left(\mathrm{Ca}^{2+}, \mathrm{Mg}^{2+}\right)(\mathrm{Cummins}$, 1980).

Although acrosome loss or exocytosis did not occur, exposure of possum spermatozoa to a capacitating medium (HIS/BSA) or wallaby spermatozoa to $10 \mu \mathrm{M}-\mathrm{A} 23187$ induced major changes within the acrosome. The acrosomal contents were changed from an essentially amorphous electrondense matrix to a collection of membrane-like vesicles. Pretreatment of possum spermatozoa with HIS/BSA, 'capacitating' medium, before ionophore exposure did not increase the degree of vesiculation achieved.

Structural changes within the acrosomal matrix have been reported for eutherian spermatozoa. Similar vesiculation of the acrosome has been described for human spermatozoa during the acrosome reaction by Nagae et al. (1986) but others have failed to confirm this finding (Suarez et al., 1986). Somewhat similar structures, identified as microtubules, have been seen in the acrosomes of monkeys and rabbits (Stambaugh \& Smith, 1978). Swelling of the acrosome and the formation of membranous vesicles within its matrix have been reported following freezing and thawing of boar spermatozoa and was suggested to be representative of capacitation (Courtens et al., 1989).

Acrosomal vesiculation like that described here has been observed within the female tract of the American opossum (Didelphis virginiana) (Rodger \& Bedford, 1982b). Opossum spermatozoa pair together via the flat acrosomal surface of their heads during epididymal transit (Biggers \& DeLamater, 1965; Olson, 1980; Temple-Smith \& Bedford, 1980; Rodger, 1982) and remain locked together until just before fertilization (Rodger \& Bedford, 1982a, b; Baggott et al., 1987; Phillips \& Fadem, 1987). Separation of paired spermatozoa in the oviducts was consistently accompanied by the appearance of empty membrane-bound vesicles in the acrosome and the disappearance of the acrosomal matrix (Rodger \& Bedford, 1982b). Further evidence of in-vivo acrosome vesiculation of marsupial spermatozoa can be seen in Fig. 11 of Breed et al. (1989): in Sminthopsis crassicaudata, as in Didelphis, the acrosomal changes are found in spermatozoa within the oviducal isthmus of a preovulatory female.

The similarity between the in-vivo vesiculation events observed in Didelphis and Sminthopsis and the in-vitro events described here for the possum and wallaby strongly argue that the acrosomal metamorphosis observed is an integral part of marsupial fertilization. Its equivalence to events in the eutherian system is unclear. It is unlikely to represent the acrosome reaction which probably occurs on the surface of the zona pellucida (Rodger \& Bedford, 1982b; Baggott et al., 1987; Breed \& Leigh, 1988). We believe that the vesiculation is likely to be preparatory to the marsupial acrosome reaction and thus more akin to the process of capacitation. If this is so, capacitation of marsupial spermatozoa differs from that in eutherians for which there are no accepted morphological indications.

Whether marsupial spermatozoa require a capacitation period and the nature and site of the acrosome reaction remain to be established. The marsupial acrosome appears far more stable than its eutherian counterpart, not being lost spontaneously or disrupted by treatment with a variety of cell activators and regulators.

This study was undertaken with the financial assistance of the Australian Research Council. The project was approved by the National Parks and Wildlife Service of NSW and the Animal Care and Ethics Committee of the University of Newcastle.

\section{References}

Austin, C.R. (1952) The "capacitation" of the mammalian sperm. Nature, Lond. 170, 326.

Baggott, L.M., Davis-Butler, S. \& Moore, H.D.M. (1987) Characterization of oestrus and timed collection of oocytes in the grey short-tailed opossum, Monodelphis domestica. J. Reprod. Fert. 79, 105-114.
Barros, C., Bedford, J.M., Franklin, L.E. \& Austin, C.R. (1967) Membrane vesiculation as a feature of the mammalian acrosome reaction. J. Cell Biol. 34, Cl-C5.

Bedford, J.M. (1983) Significance of the need for sperm capacitation before fertilization in eutherian mammals. Biol. Reprod. 28, 108-120. 
Bedford, J.M., Moore, H.D.M. \& Franklin, L.E. (1979) Significance of the equatorial segment of the acrosome of the spermatozoa in eutherian mammals. Expl. Cell Res. 119, 119-126.

Biggers, J.D. \& DeLamater, E.D. (1965) Marsupial spermatozoa pairing in the epididymis of American forms. Nature, Lond. 208, 402-404.

Brackett, B.G. \& Oliphant, G. (1975) Capacitation of rabbit sperm in vitro. Biol. Reprod. 12, 260-274.

Breed, W.G. \& Leigh, C.M. (1988) Morphological observations on sperm-egg interactions during in vivo fertilization in the dasyurid marsupial, Sminthopsis crassicaudata. Gamete Res. 19, 131-149.

Breed, W.G., Leigh, C.M. \& Bennett, J.H. (1989) Sperm morphology and storage in the female reproductive tract of the fat-tailed dunnart, Sminthopsis crassicaudata (Marsupiala: Dasyuridae). Gamete Res. 23, $61-75$.

Bryan, J.H.D. (1970) An eosin-fast green-naphthol yellow mixture for differential staining of cytologic components in mammalian spermatozoa. Stain Technol. 45, 231-236.

Chang, M.C. (1951) Fertilizing capacity of spermatozoa deposited in the Fallopian tube. Nature, Lond. 168 , 697-699.

Courtens, J.L., Ekwall, H., Paquignon, M. \& Plöen, L. (1989) Preliminary study of water and some element contents in boar spermatozoa, before, during and after freezing. J. Reprod. Fert. 87, 613-626.

Cummins, J.M. (1980) Decondensation of sperm nuclei of Australian marsupials: effects of air drying and of calcium and magnesium. Gamete Res. 3, 351-367.

Dudenhausen, E. \& Talbot, P. (1982) Detection and kinetics of the normal acrosome reaction of mouse sperm. Gamete Res. 6, 257-265.

Harding, H.R., Carrick, F.N. \& Shorey, C.D. (1979) Special features of sperm structure and function in marsupials. In The Spermatozoon, pp. 289-303. Eds D. Fawcett \& J. M. Bedford. Urban \& Schwarzenberg, Baltimore.

Lee, M.A., Kopf, G.S. \& Storey, B.T. (1987) Effects of phorbol esters and a diacylglycerol on the mouse sperm acrosome reaction induced by the zona pellucida. Biol. Reprod. 36, 617-627.

Meizel, S. (1985) Molecules that initiate or help stimulate the acrosome reaction by their interaction with the mammalian sperm surface. Am. J. Anat. 174, 285-302.

Nagae, T., Yanagimachi, R., Srivastava, P.N. \& Yanagimachi, H. (1986) Acrosome reaction in human spermatozoa. Fert. Steril. 45, 701-707.

Oliphant, G., Reynolds, A.B. \& Thomas, T.S. (1985) Sperm surface components involved in the control of the acrosome reaction. Am. J. Anat. 174, 269-283.

Olson, G.E. (1980) Changes in intramembranous particle distribution in the plasma membrane of Didelphis virginiana spermatozoa during maturation in the epididymis. Anat. Rec. 197, 471-488.
Phillips, D.M. \& Fadem, B.H. (1987) The oocyte of a new world marsupial, Monodelphis domestica: structure, formation, and function of the enveloping mucoid layer. J. exp. Zool. 242, 363-371.

Rodger, J.C. (1982) The testis and its excurrent ducts in American Caenolestid and Didelphid marsupials. Am. J. Anat. 163, 269-282.

Rodger, J.C. (1991) Fertilization of Marsupials. In $A$ Comparative Overview of Mammalian Fertilization. Eds B. Dunbar \& M. O'Rand. Plenum Press, New York (in press)

Rodger, J.C. \& Bedford, J.M. (1982a) Induction of oestrus, recovery of gametes, and the timing of fertilization events in the opossum, Didelphis virginiana. J. Reprod. Fert. 64, 159-169.

Rodger, J.C. \& Bedford, J.M. (1982b) Separation of sperm pairs and sperm-egg interaction in the opossum, Didelphis virginiana. J. Reprod. Fert. 64, 171-179.

Rodger, J.C. \& Mate, K.E. (1988) A PMSG/GnRH method for the superovulation of the monovulatory brush-tailed possum (Trichosurus vulpecula). $J$. Reprod. Fert. 83, 885-891.

Rodger, J.C. \& Pollitt, C.C. (1981) Radiographic examination of electroejaculation in marsupials. Biol. Reprod. 24, 1125-1134.

Rodger, J.C. \& White, I.G. (1978) The collection, handling and some properties of marsupial semen. Symp. zool. Soc. Lond. 43, 289-301.

Rogers, B.J. (1978) Mammalian sperm capacitation and fertilization in vitro: a critique of methodology. Gamete Res. 1, 165-223.

Selwood, L. \& McCallum, F. (1987) Relationship between longevity of spermatozoa after insemination and the percentage of normal embryos in brown marsupial mice (Antechinus stuartii). J. Reprod. Fert. 79, 495-503.

Shams-Borhan, G. \& Harrison, R.A.P. (1981) Production, characterization, and use of ionophore-induced, calcium-dependent acrosome reaction in ram spermatozoa. Gamete Res. 4, 407-432.

Stambaugh, R. \& Smith, M. (1978) Tubulin and microtubule like structures in mammalian acrosomes. $J$. exp. Zool. 203, 135-141.

Suarez, S.S., Wolf, D.P. \& Meizel, S. (1986) Induction of the acrosome reaction in human sperm by a fraction of human follicular fluid. Gamete Res. 14, 107-121.

Temple-Smith, P.D. (1987) Sperm structure and marsupial phylogeny. In Possums and Opossums: Studies in Evolution, pp. 171-193. Ed. M. Archer. Surrey Beatty and Sons and the R. Zool. Soc. NSW, Sydney.

Temple-Smith, P.D. \& Bedford, J.M. (1980) Sperm maturation and the formation of sperm pairs in the epididymis of the opossum, Didelphis virginia. J. exp. Zool. 214, 161-171.

Yanagimachi, R. (1988) Mammalian fertilization. In The Physiology of Reproduction, vol. 1, pp. 135-185. Eds E. Knobil \& J. Neill. Raven Press, New York.

Received 23 February 1990 